PONTIFÍCIA UNIVERSIDADE CATÓLICA DO RIO DE JANEIRO

\title{
A estratégia de comunicação online das Distribuidoras de valores mobiliários
}

\author{
Rafaela Nissenbaum
}

Trabalho de Conclusão de Curso

CENTRO DE CIÊNCIAS SOCIAIS - CCS

DePARTAMENTO de AdMINISTRAÇÃo

Graduação em Administração de Empresas 


\title{
A estratégia de comunicação online das DTVMs no varejo
}

\author{
Trabalho de Conclusão de Curso
}

Trabalho de Conclusão de Curso, apresentado ao programa de graduação em Administração da PUC-Rio como requisito parcial para a obtenção do titulo de graduação em Administração.

Orientadora: Alessandra Baiocchi A. Corrêa

Rio de Janeiro

Junho de 2017. 


\section{Agradecimentos}

A minha orientadora Alessandra Baiocchi, que tanto me inspira e que me deu todo seu apoio e suporte e que guardarei para sempre como uma grande referência na minha vida.

Aos meus pais e irmão, que durante esses 4 anos e meio aguentaram todos os meus surtos de stress e de alegria quase sem reclamar. À toda minha família, que ao longo da faculdade sempre me apoiou e esteve totalmente presente nas minhas conquistas, reconhecendo meus esforços.

Às minhas amigas e amigos que tonaram todos os momentos até hoje mais leves e divertidos como devem ser. Agradeço especialmente às minhas duas amigas especiais que me acompanharam na minha trajetória na PUC Rio, Carolina Padilha e Giulia Gazaneo, e que espero ter comigo para sempre.

Aos meus colegas de trabalho que durante os dois anos em que trabalhei e estudei ao mesmo tempo, foram sempre muito compreensivos e atenciosos comigo. 


\section{Resumo}

NISSENBAUM, Rafaela. BAIOCCHI, Alessandra. A estratégia de comunicação online das DTVMs no varejo. Rio de Janeiro, 2017. Número de páginas p. 33 Trabalho de Conclusão de Curso - Departamento de Administração. Pontifícia Universidade Católica do Rio de Janeiro.

Com os avanços tecnológicos e as mudanças no mercado financeiro o marketing das empresas do setor vem sofrendo alterações. Com o tempo, se tornou necessário o uso de redes sociais nas estratégias de comunicações e junto a isso a linguagem também foi alvo de renovação.

Com isso, o presente trabalho, estuda as melhores formas de se comunicar com o público-alvo através dos mais novos e adequados canais de comunicação. O estudo foca seus esforços no caso da empresa Órama Investimentos, grande player do mercado de Distribuidoras de Títulos e Valores Mobiliários. Para tal, foram feitas pesquisas sobre o ambiente que se encontra e a história de sua transformação, assim como entrevistas com profissionais e conceitos de marketing que embasassem a escolha da estratégia ideal para a empresa.

\section{Palavras-chave}

Mercado Financeiro, DTVM, Estratégia de Marketing, Comunicação Online, Redes Sociais 


\section{Abstract}

NISSENBAUM, Rafaela. BAIOCCHI, Alessandra. A estratégia de comunicação online das DTVMs no varejo. Rio de Janeiro, 2017. Número de páginas p. 33 Trabalho de Conclusão de Curso - Departamento de Administração. Pontifícia Universidade Católica do Rio de Janeiro.

With technological advances and changes in the financial market, marketing financial companies has been undergoing significant changes. It is now mandatory to integrate communication strategies with social networks. The marketing language has also been subject to renewal. Taking this into account, the present study, studies the best ways to communicate with the target audience through the newest communication channels.

The study focuses its efforts on the case of Órama Investimentos, a major distributor in Brazil's Hedge Funds and Bonds market. To this end, research was done on the social network environment, and its transformation's history. This thesis also contains interviews with professionals, who detail the marketing concepts that were chosen to form the company's marketing strategy.

Key-words

Financial Market, Distribution, Marketing Strategy, Online Communication, Social Media 


\section{Sumário}

1 Introdução 8

1.1. Motivação 8

1.2. Descrição da situação problema: dados do setor e ambiente externo 8

1.2.1 A desbancarização no mundo 8

1.2.2. Os bancos no Brasil 9

1.2.3. O mercado de investimentos e varejo no Brasil 10

1.3. Delimitações 13

1.4. Relevância 13

2 Passos da Pesquisa 15

2.1. Etapa 1

2.2. Etapa 2

2.3. Etapa $3 \quad 15$

2.4. Etapa 4

2.5. Etapa 5

2.6. Etapa $6 \quad 16$

2.7. Etapa $7 \quad 16$

3 Contextualização - A empresa Órama 18

3.1. Ambiente Interno - Histórico e Atualidade 18

3.2. Dados da Organização 18

4 Pesquisa com principais concorrentes $\quad 21$

5 Análise dos anúncios da Órama $\quad 27$

5.1. Análise das entrevistas 28

6 Considerações Finais 31

$\begin{array}{ll}\text { Anexo 1: Roteiro das entrevistas } & 37\end{array}$

Anexo 2: Convite Entrevistas 38 


\section{Índice de Figuras}

Figura 1: Crescimento do número de Gestoras Independentes no Brasil -

Elaborado pela autora com base em dados ANBIMA - Consolidado

Histórico de Fundos de Investimento - Fevereiro/2017

Figura 2: Cadastro de Reclamação Fundamentada, (2015) - Procon............... 10

Figura 3:Produzido pela autora com base nos dados ANBIMA e ICI, 2015. ....11

Figura 4: Produzido pela autora com base nos dados do relatório ANBIMA, 2016. 12

Figura 5: OECD - Consumer confidence index (CCI) - Out, 2016 12

Figura 6: Post - Facebook Órama. 19

Figura 7: E-mail Marketing - Órama. 20

Figura 8: Dados retirados da ferramenta de envio de e-mail da Órama - RD

Station. 20

Figura 9: Banner Home - Órama Investimentos 21

Figura 10: Banner Home - Rico.com.vc. .22

Figura 11: Banner Home - XP Investimentos .22

Figura 12: Banner Home - Easynvest. .22

Figura 13: Post - Facebook Easynvest 25

Figura 14: Anúncio Institucional - Facebook Órama.. 27

Figura 15: Anúncio Tesouro - Facebook Órama. .28

Figura 16: Tabela Google Analytics - Facebook Órama .28

\section{Índice de Tabelas}




\section{Introdução}

\subsection{Motivação}

O tema do presente trabalho é o estudo da estratégia de comunicação online das Distribuidoras de títulos e valores mobiliários 1 .

A motivação desta pesquisa vem da junção do interesse da autora por mercado financeiro, onde trabalha, e teorias de marketing estudadas no curso de Administração de Empresas da PUC-Rio.

A autora atualmente trabalha na Órama Investimentos, como Analista de Métricas, e tem amplo acesso aos dados da empresa para poder fazer as devidas pesquisas e entrevistas.

Hoje, a Órama ainda encontra dificuldades para estabelecer um padrão que conste com a "fórmula correta" para se comunicar. São feitos diversos testes tanto de conteúdo como de imagem para se analisar os resultados, mas mesmo assim ainda não pôde ser constatado o formato ideal. Ao obter esse estudo, a empresa poderá utilizá-lo como um material de apoio na construção de suas comunicações, com o objetivo de ser cada vez mais certeira e bem posicionada.

\subsection{Descrição da situação problema: dados do setor e ambiente externo}

\subsubsection{A desbancarização no mundo}

O termo desbancarização significa deixar de fazer os investimentos somente no sistema bancário brasileiro, procurar por novas fontes de produtos mais vantajosos. (Bremenkamp Consultoria Financeira) A recente história da desbancarização do Brasil aconteceu anteriormente em pais mais desenvolvidos. De acordo com artigo do Brasil Econômico, nos EUA, na década de 60 e 70 houve um crescimento da classe média no pós-guerra, que provocou o surgimento de investidores mais preocupados em buscar a maior rentabilidade para o seu dinheiro visando poupar para a aposentadoria. Em maio de 1975, há

\footnotetext{
${ }^{1}$ Apesar da empresa em questão - Órama Investimentos - ser uma Distribuidora, as concorrentes em análise são Corretoras de Títulos e Valores mobiliários, o que atualmente, com novas regras na legislação, não possui grandes diferenças.
} 
o fim da corretagem fixa, marcando o início da expansão da Charles Schwab, através de descontos frente aos seus maiores concorrentes: Merrill Lynch e Bank of America. (TARABORELLI FERNANDA, 2015)

No ano de 2000 o processo começa a ficar visível para o brasileiro, quando se inicia o boom das gestoras independentes no Brasil (Figura 1).

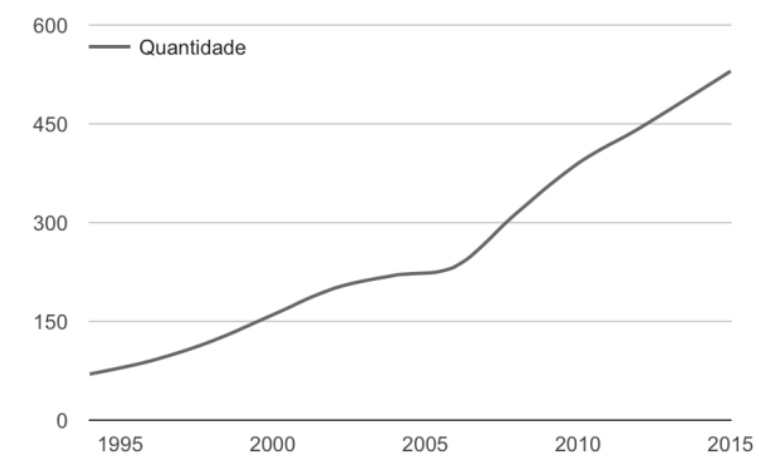

Figura 1: Crescimento do número de Gestoras Independentes no Brasil - Elaborado pela autora com base em dados ANBIMA - Consolidado Histórico de Fundos de Investimento - Fevereiro/2017.

Em maio de 2012, no Brasil, o Governo altera as regras da poupança, abrindo portas para outras alternativas de investimento (PORTAL BRASIL, 2012). Expandindo as possibilidades e fazendo com que os investidores tenham melhores opções de rendimento para seus recursos.

Em 2015 a Charles Schwab passou a ter USD 2.7 trilhões sob gestão (CHARLES SCHWAB ANNUAL REPORT, 2015) e passa a ter USD 42 bilhões de valor de mercado (NYSE, 2016).

Através do Ranking "Gestores de Fundos de Investimentos Setembro/2016" podemos encontrar dados extremamente relevantes. Os investidores de varejo que aplicam em fundos de gestores independentes, ou seja, fora dos bancos, totalizam $1,1 \%$ do Patrimônio Líquido total. Se adicionarmos os investidores de varejo de alta renda, o percentual muda para $2,3 \%$ e, incluindo os investidores do segmento private, integralizam $13,5 \%$ do $\mathrm{PL}$ total. Já nos EUA, a indústria, em 2015, possuía Patrimônio Líquido de US\$18,1 trilhões (FACT BOOK ICI, 2015) e é composta da seguinte maneira: os investidores de varejo (i.e.households) detêm a maioria dos ativos em fundos $89 \%$ - e $79 \%$ dos agentes, são independentes e fazem a gestão de $67 \%$ dos ativos.

\subsubsection{Os bancos no Brasil}

"O setor bancário brasileiro passou por um processo de mudanças 
profundas nos últimos dez anos, o que provocou uma onda de fusões e aquisições (F\&As) bancárias" (ANPEC, 2009, p. 1).

A tendência à um monopólio dos bancos brasileiros é cada vez uma realidade mais próxima. (ANPEC, 2009)

Junto a isso podemos ver um movimento muito claro da piora do relacionamento dos clientes com seus respectivos bancos. Em um estudo do Valor Econômico (2016) muitos bancos se concentram nos "top 20" de reclamações de telecomunicações, como mostra a figura 2.

\begin{tabular}{clr}
\hline Posição & EmPresa & Total \\
\hline $\mathbf{1}$ & GRUPO CLARO / NET / EMBRATEL (AMÉRICA MÓVIL) & 5.883 \\
\hline $\mathbf{2}$ & GRUPO VIVO/TELEFÔNICA & 3.901 \\
\hline $\mathbf{3}$ & SKY BRASIL SERVIÇOS LTDA. & 2.731 \\
\hline $\mathbf{4}$ & TIM CELULAR S/A & 2.351 \\
\hline $\mathbf{5}$ & GRUPO PÃO DE AÇÚCAR / EXTRA / PONTOFRIO.COM / CASASBAHIA.COM / & 2.349 \\
\hline $\mathbf{6}$ & GASAS BAHIA / PONTO FRIO & 1.830 \\
\hline $\mathbf{7}$ & GRUPO ITAU UNIBANCO & 1.595 \\
\hline $\mathbf{8}$ & GRUPO UNIMED & 1.497 \\
\hline $\mathbf{9}$ & GRUPO OI & 1.388 \\
\hline $\mathbf{1 0}$ & GRUPO BRADESCO & 1.171 \\
\hline $\mathbf{1 1}$ & GRUPO SONY & 973 \\
\hline $\mathbf{1 2}$ & ELETROPAULO METROPOLITANA ELETRICIDADE DE S PAULO & 774 \\
\hline $\mathbf{1 3}$ & GRUPO LENOVO CCE & 750 \\
\hline $\mathbf{1 4}$ & CIA DE SANEAMENTO BASICO DO ESTADO DE SAO PAULO & 680 \\
\hline $\mathbf{1 5}$ & NEXTEL TELECOMUNICAÇÕES LTDA & 634 \\
\hline $\mathbf{1 6}$ & SAMSUNG ELETRONICA DA AMAZONIA & 613 \\
\hline $\mathbf{1 7}$ & GRUPO SANTANDER & 477 \\
\hline $\mathbf{1 8}$ & GRUPO ELECTROLUX & 459 \\
\hline $\mathbf{1 9}$ & GRUPO B2W / AMERICANAS.COM / SUBMARINO / SHOPTIME / SOUBARATO / & 411 \\
\hline $\mathbf{2 0}$ & LOJAS AMERICANAS & 386 \\
\hline & GRUPO ANHANGUERA / UNOPAR (KROTON) & \\
\hline
\end{tabular}

Figura 2: Cadastro de Reclamação Fundamentada, (2015) - Procon

Conforme vimos na figura 3 , é elevado o número de reclamações no PROCON sobre os serviços bancários (Cadastro de Reclamação Fundamentada, 2015). Isso indica uma insatisfação da população com relação à qualidade do atendimento do setor em questão.

\subsubsection{O mercado de investimentos e varejo no Brasil}

No Brasil, de acordo com informações provenientes do ICl (Investment Company Institute, 2015) e do Anuário ANBIMA (2015), é constante o surgimento de novas oportunidades de investimentos. Os gráficos apresentados na sequência ilustram o volume de recursos em Fundos de Investimento ao redor do mundo. 


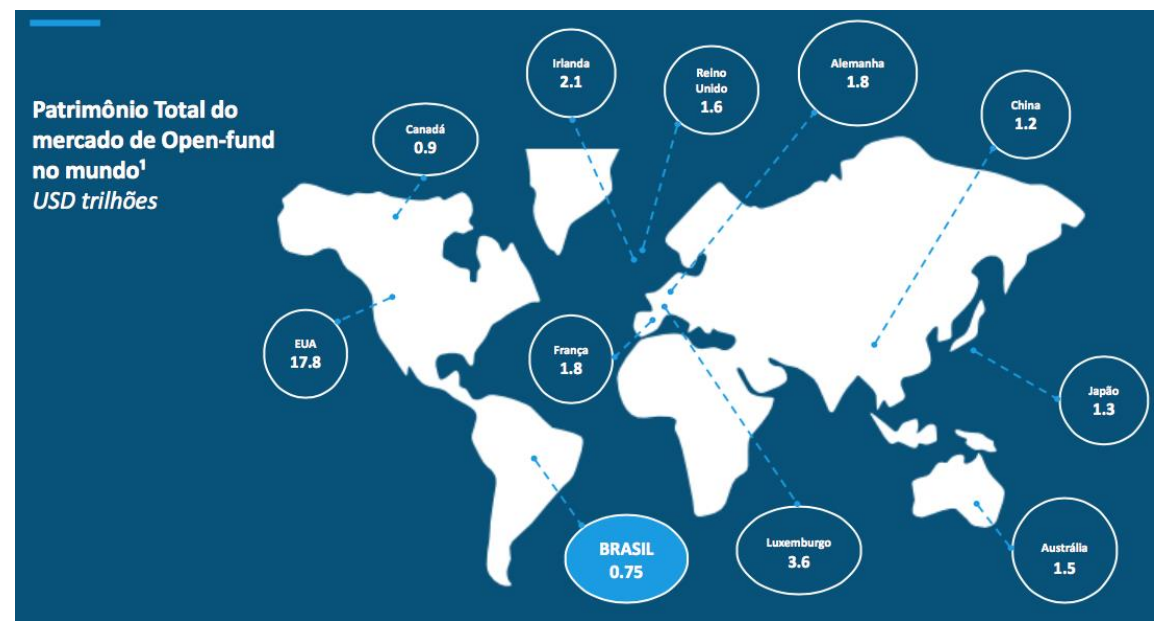

Figura 3:Produzido pela autora com base nos dados ANBIMA e ICI, 2015.

No esquema apresentado na Figura 3, podemos ver que da lista em análise, o Brasil ainda é o menor Patrimônio neste tipo de investimento, ou seja, ainda é um mercado de possível expansão.

Outro ponto de extrema importância é a distribuição de recursos em diferentes tipos de investimentos. No esquema ilustrado na Figura 4, elaborado com base em dados do relatório Anbima de 2016 é possível fazer diversas análises. Os investimentos na poupança, apesar de terem reduzido nos últimos dois anos, ainda é o maior volume em disparado. Ele hoje concentra $84 \%$ de clientes do varejo, representando um total de 54 milhões de clientes. Já o volume de recursos em Fundos de Investimentos está em um crescente constante desde o ano de 2012. Esse valor está distribuído de forma que $87,3 \%$ do volume está alocado em Fundos de Renda Fixa e os outros $12,7 \%$ em outros tipos de Fundos.

Quando tratamos de Títulos e Valores Mobiliários temos um cenário parecido com o de Fundos de Investimento, que também está em expansão. Hoje ele está dividido da seguinte maneira: sua maior parte em Títulos Privados (91,8\%), Títulos Públicos com 3,5\% do volume e o restante (4,7\%) em outros tipos de Fundos. Além disso, podemos acompanhar também o avanço exponencial do varejo no mercado de Renda Fixa, onde a emissão de LCI e LCA, passaram de $34,3 \%$ (2014) para 47,5\% (06/2016) do número de investidores (ANBIMA, 2016). 


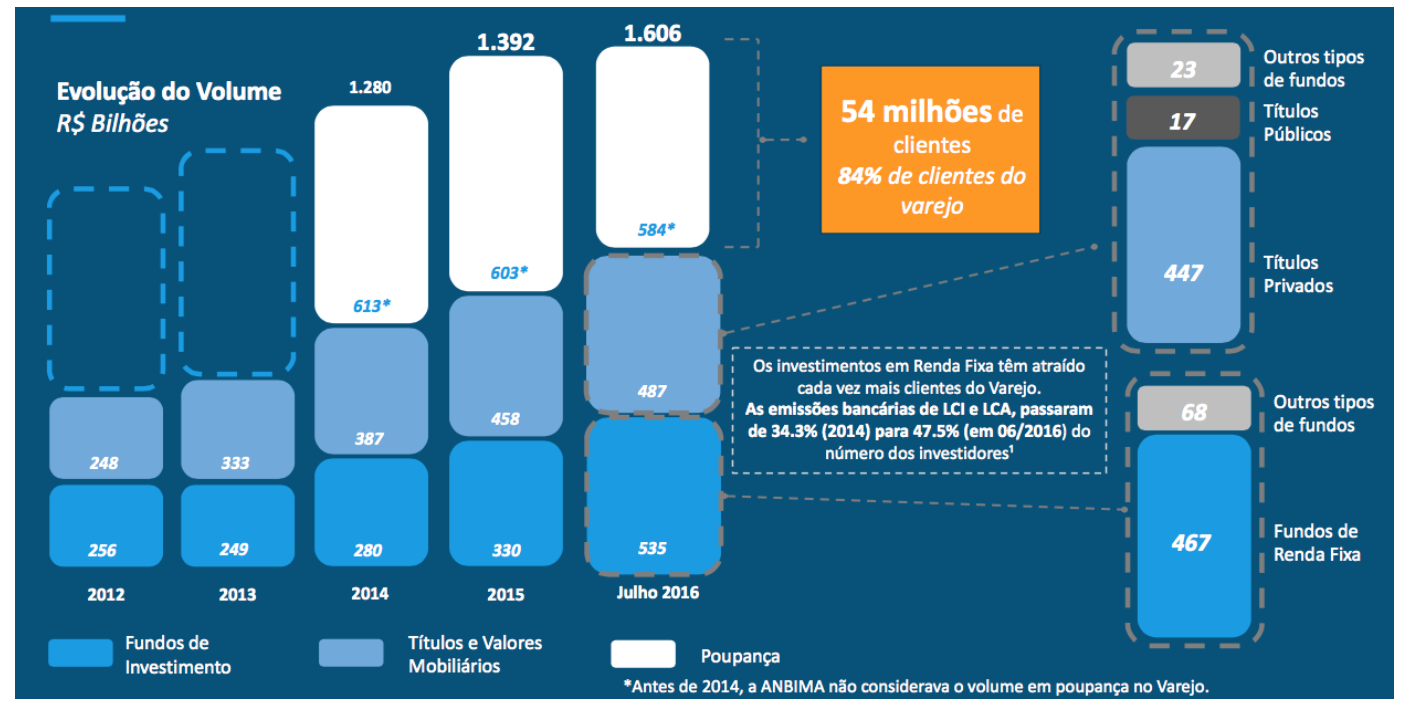

Figura 4: Produzido pela autora com base nos dados do relatório ANBIMA, 2016.

O brasileiro, como interpretado por estudos da OECD (Organização de Cooperação e Desenvolvimento Econômico, 2016), ainda é um investidor bastante inseguro e avesso ao risco. A OECD demonstra através do indicador $\mathrm{CCl}$ (Consumer confidence index) que a confiança do consumidor brasileiro é extremamente prejudicada. Apesar de ter tido um recente aumento, sofreu quedas bruscas em 2014 e 2015 que ainda não foram recuperadas, e quando comparadas aos EUA demonstram um grande problema.

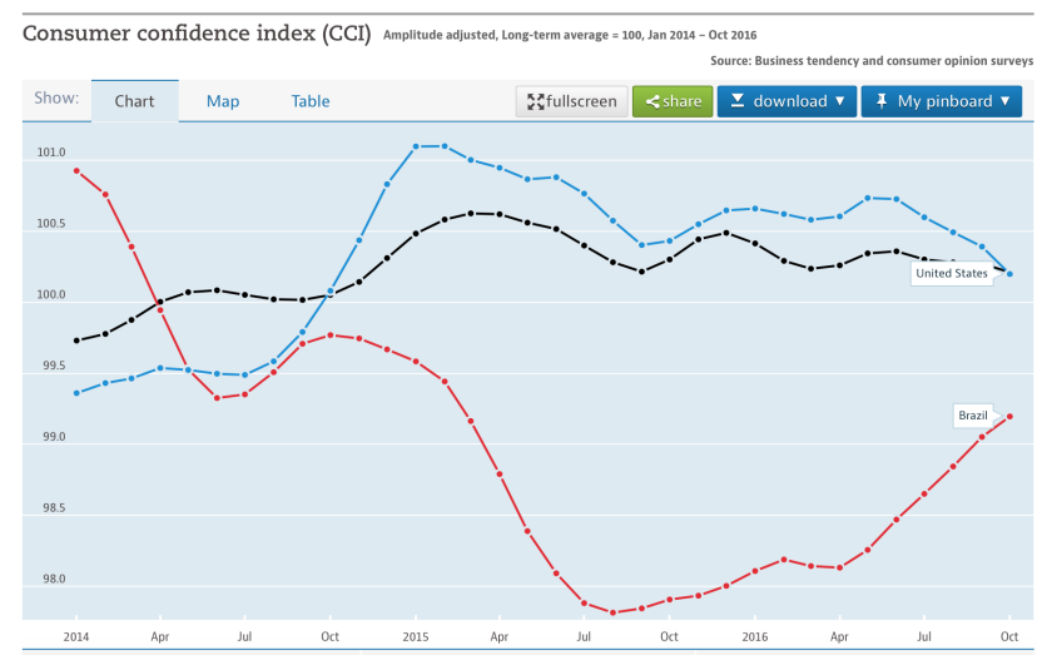

Figura 5: OECD - Consumer confidence index (CCI) - Out, 2016

De acordo com o estudo "How's life in Brazil" (OECD, 2016) a população brasileira ainda é muito prejudicada em alguns pontos primordiais, como renda, desemprego e educação. A renda do brasileiro ainda é muito baixa em comparação com outros países, a taxa de desemprego é muito elevada e o nível de escolaridade muito baixo. 
Este trabalho pretende contribuir para desenvolver a estratégia de comunicação online mais adequada para conseguir atrair e converter o público alvo da Órama DTVM.

Este estudo pretende focar seus esforços em análises do mercado brasileiro, e não estrangeiro - tratado somente na contextualização do tema. As empresas concorrentes estudadas são da mesma nacionalidade da empresa principal em questão. Essa restrição ocorre pelas amplas divergências de legislação que ocorrem entre países diferentes, fazendo com que as formas de investimentos sejam diferentes.

Os estudos e artigos utilizados como base de pesquisa para esse trabalho são, em sua maioria, feitos a partir de 2010, mantendo a realidade mais próxima da atual por conta da constante evolução do mercado em questão.

O público que será acompanhado nos estudos são jovens investidores, dos 18 aos 30 anos, ou seja, que estão no início dos seus investimentos para o futuro. Este segmento, de acordo com pesquisa do IBGE de 2016, está em constante crescimento e evolução, o que o torna ainda mais atrativo e desafiador para as empresas conseguirem atingi-los.

Embora todos os meios de comunicação sejam de extrema importância, o presente estudo foca seus esforços somente na estratégia de comunicação online.

\subsection{Relevância}

As informações que este estudo pretende produzir podem ser de extremo interesse da empresa em questão - Órama DTVM - pois irá auxiliála na elaboração de uma estratégia de comunicação online de forma eficaz e eficiente. Ou seja, ajuda na utilização dos recursos mais apropriados, da melhor maneira possível para o seu público-alvo.

Os resultados a serem alcançados também poderão ser úteis profissionalmente para a autora posto que ela poderá introduzir às conclusões chegadas às resoluções de diversos problemas da sua rotina de trabalho na área de marketing da empresa.

Além disso, o tema tratado é pode ser relevante para a academia, 
visto que ao iniciar o processo de pesquisa no desenvolvimento do trabalho em questão, não foram encontrados muitos materiais com informações sobre estratégia de comunicação digital de empresas do ramo de mercado financeiros. 


\subsection{Etapa 1}

A primeira etapa da pesquisa do trabalho foi de cunho exploratório, via entrevistas com colegas e gerentes da empresa Órama Investimentos. Através delas foi decidido um tema relevante para o trabalho em questão, que era um problema recorrente, reconhecido por todos na empresa e com grande relevância.

\subsection{Etapa 2}

Em seguida, foram feitas diversas consultas a diferentes relatórios do setor. Entre os meses setembro e novembro de 2017, foram feitas buscas onde foram usadas fontes de dados secundárias para contextualizar o problema e explicar o setor.

\subsection{Etapa 3}

Nesta etapa foi feita a decisão de objeto de estudo. O estudo se focou nos resultados de mídia da Rede Social Facebook. Isso foi feito por ser hoje o principal meio de comunicação da empresa e onde é alocada a maior parte de seu orçamento. Além disso, foi também um ponto de bastante volatilidade quando tratado nas entrevistas com os colaboradores da empresa.

\subsection{Etapa 4}

A quarta parte da pesquisa foi a de busca de informações dos concorrentes. Nesse momento foram selecionados diversos concorrentes para fazer a análise, mas para se aprofundar foram escolhidos somente 4 , os julgados pela gerente de Marketing da empresa como principais e mais diretos concorrentes da Órama.

\subsection{Etapa 5}


Nesta etapa foi feita a pesquisa interna, onde foram selecionadas quais as comunicações da Órama que seriam diagnosticadas. Para isso foram escolhidos banners recentes, impulsionados e que tivessem trazido algum retorno para a empresa. Além disso, foi bastante relevante escolher imagens que trouxessem o que é feito com mais frequência pela empresa, ou seja, mais padrões com o que fazem sempre. Nesse momento houve também um recorte temporal, onde foram analisados os resultados de 17 a 20 de abril de 2017.

\subsection{Etapa 6}

Como sexta etapa de pesquisa foram feitas entrevistas com profissionais da área. Foram feitas 4 entrevistas, sendo uma delas com a Gerente de Marketing da Órama - CB. O objetivo dessas entrevistas foi investigar questões de marketing que pudessem gerar a melhor solução para a empresa, respondendo ao objetivo de pesquisa do trabalho em questão. Para selecionar os entrevistados, foi publicado em uma rede social de alunos e exalunos um convite para participar de entrevista (Anexo 2). Em seguida, as entrevistas foram feitas com três profissionais para ajudar no processo do trabalho.

\begin{tabular}{|l|l|l|l|l|}
\hline Nome Fictício & Área de atuação & Data & Formato & Registro \\
\hline FP & Mkt Digital - Google & $18 / 04 / 17$ & Telefone & Gravado \\
\hline ED & Marketing - L'Óreal & $21 / 04 / 17$ & Skype & Gravado \\
\hline CA & Mercado Imobiliário & $21 / 04 / 17$ & Telefone & Gravado \\
\hline CB & Marketing - Órama & $03 / 05 / 17$ & Pessoal & Gravado \\
\hline
\end{tabular}

Tabela 1: Entrevistados TCC - Elaborado pela autora

O roteiro das entrevistas foi estruturado e com perguntas abertas, que se encontra em anexo no fim do trabalho. (Anexo 1)

\subsection{Etapa 7}


Como sétima e última etapa de pesquisa, foi feita uma análise dos resultados dos passos anteriores em busca de uma resposta para o objetivo de pesquisa do presente trabalho. 


\section{Contextualização - A empresa Órama}

\subsection{Ambiente Interno - Histórico e Atualidade}

A Órama foi criada em 2011 por profissionais experientes do mercado, foi a primeira plataforma digital de investimento no Brasil, premiada pela Amazon Web Services como uma das empresas mais inovadoras em serviços financeiros. Presente em todo o Brasil com uma estrutura $100 \%$ online, a Órama está comprometida com a entrega do melhor serviço para que o Brasileiro possa investir de forma consciente e transparente.

No início a empresa contava apenas com fundos de investimento em seu portfólio de produtos, hoje, devido às movimentações do cenário macroeconômico brasileiro, foram inseridos novos produtos (Títulos de Renda Fixa - CDB, LCI, LCA e LC). Além disso, a empresa tem se aprofundado cada vez mais no uso das redes sociais para comunicação, contando atualmente com cinco redes sociais diferentes para isso. São elas: Facebook, Twitter, Mypush, Instagram e Youtube.

\subsection{Dados da Organização}

A empresa conta com grandes diferenciais no mercado em que atua: democratização do acesso à investimentos de alta qualidade com aplicação mínima de mil reais; distribuição dos melhores fundos de investimento de gestores independentes; ferramentas de análise dentro da plataforma online; conteúdo online de educação financeira grátis; segurança, por se tratar de uma plataforma independente focada em oferecer o que é melhor pro cliente; consultoria especializada por uma equipe orientada para ajudar os clientes a escolher o melhor investimento pro seu perfil e suporte totalmente online.

A comunicação da Órama com o seu público é feita através de diversos canais próprios (blog, e-mail, assessoria de imprensa, redes sociais, youtube e adwords) e de parceiros (Portal Administradores, ADVFN, Aplicativo Renda Fixa e Investing). Além de estar presente nos parceiros, procura explorar o maior número de mídias diferentes dentro 
deles, como artigos, banner, email e etc.

\subsection{Comunicação com os Clientes}

Atualmente a empresa faz suas comunicações em diversos canais, sendo os dois principais o Facebook e o E-mail marketing para a sua base própria. Diversas vezes são necessárias alterações nas peças e é possível ver melhorias rápidas de resultados com poucas mudanças. Nas Figura $6 \mathrm{e}$ 7 podemos ver o resultado de duas campanhas.

A primeira, no Facebook, um post de Produto - um fundo de investimento específico - com o seguinte texto: "Você já imaginou curtir o carnaval com o dobro do dinheiro que você tem hoje? Pois é... quem investiu no Fundo Flag Ações no dia 10/02/2016, Quarta-Feira de Cinzas do ano passado, acumulou um retorno de $114,52 \%$ até o dia 15/02/2017. Ou seja, se tivesse investido um valor de $R \$ 5.000$ naquela data, hoje poderia resgatar o equivalente a $R \$ 10.726$. Não perca tempo! \#invistacerto Saiba mais em http://bit.ly/2IW3BiX".
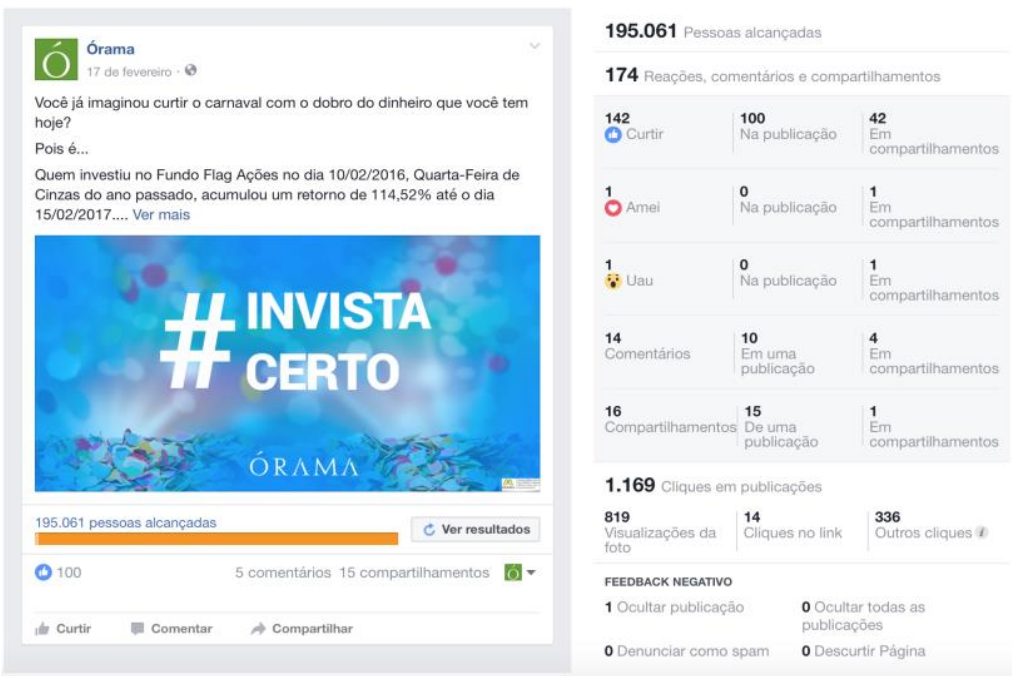

Figura 6: Post - Facebook Órama

$\mathrm{Na}$ imagem da figura 6, é possível verificar os resultados da postagem, que obteve 100 curtidas, 5 comentários, 15 compartilhamentos, 14 cliques no link e 195.061 pessoas alcançadas. Apesar do engajamento ${ }^{2}$ ter sido baixo e o alcance alto, os sistemas da empresa demonstram um aumento significativo de aplicações e busca pelo fundo Flag FIC FIA, citado na postagem.

\footnotetext{
2 "Engajamento é envolvimento, interação, relacionamento com a marca, que vai além do número de seguidores em uma rede social ou likes em uma postagem”. REZ, 2014
} 
Um segundo exemplo é o E-mail Marketing da figura 7. Que foi enviado a usuários que já iniciaram o cadastro, mas não terminaram, vendendo duas opções de títulos de Renda fixa exclusivos para eles.

\section{ÓR $\Lambda \mathrm{M} \Lambda$}

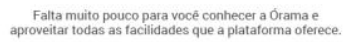
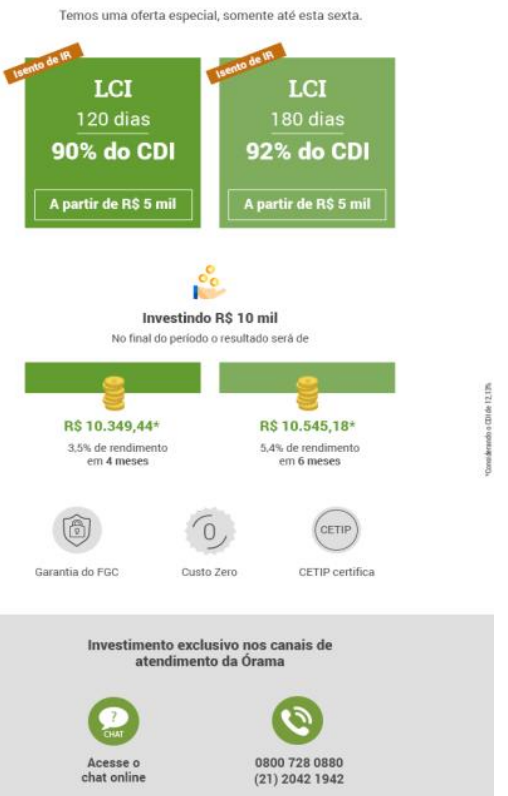

Figura 7: E-mail Marketing - Órama

A comunicação acima, da figura 7 , obteve um excelente resultado de abertura, com $27 \%$, enquanto a taxa de clique foi bastante baixa, de acordo com a imagem dos resultados inserida na figura 8 .

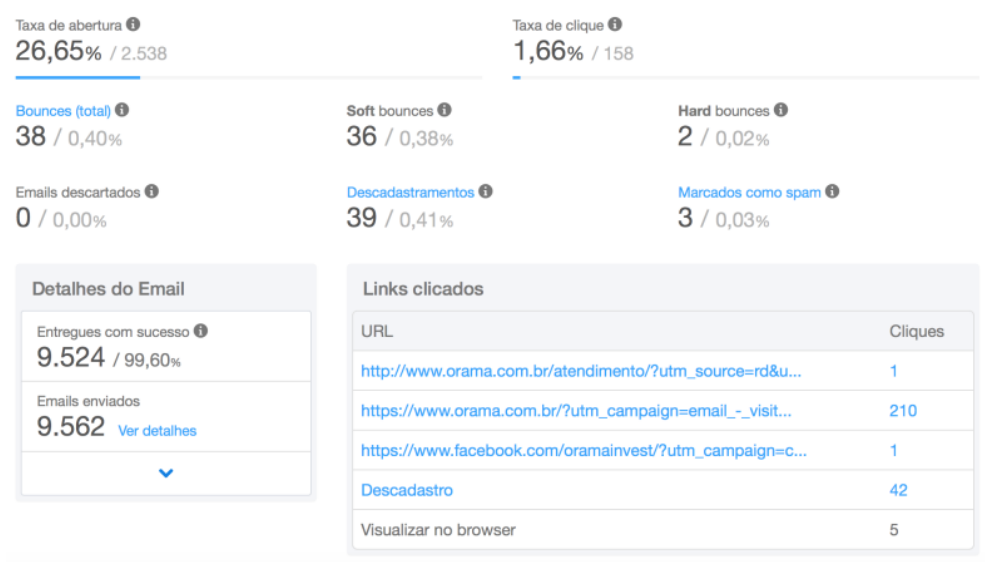

Figura 8: Dados retirados da ferramenta de envio de e-mail da Órama - RD Station. 
A partir do contexto em que há uma grande massificação da comunicação do tema "dinheiro", com o surgimento dos novos meios de investimentos, o investidor começa a ser extremamente atingido, em canais diversos, pelas plataformas online com campanhas de produtos variados.

É possível fazer uma análise das comunicações das distribuidoras de investimentos e notar que apesar de estarem em torno do mesmo tema, cada uma possui suas singularidades, formatos e estratégias de marketing diferentes para chegar no seu público alvo e convertê-lo. Nas figuras 9, 10, 11 e 12 é possível analisar o banner de entrada de 4 grandes concorrentes, voltadas para o mesmo público, mas cada uma com a sua essência.

A figura 9 representa o banner de entrada ${ }^{3}$ da Órama, que inclui seu slogan principal, seus maiores argumentos de venda e na parte de baixo a divisão entre três perfis de investidor diferentes: i) o que está a procura de um produto diretamente, ii) o que não entende do assunto, quer indicação de onde investir mas não faz questão de aprender sobre o assunto e, iii) 0 que antes de começar a investir quer aprender e entender sobre o assunto.

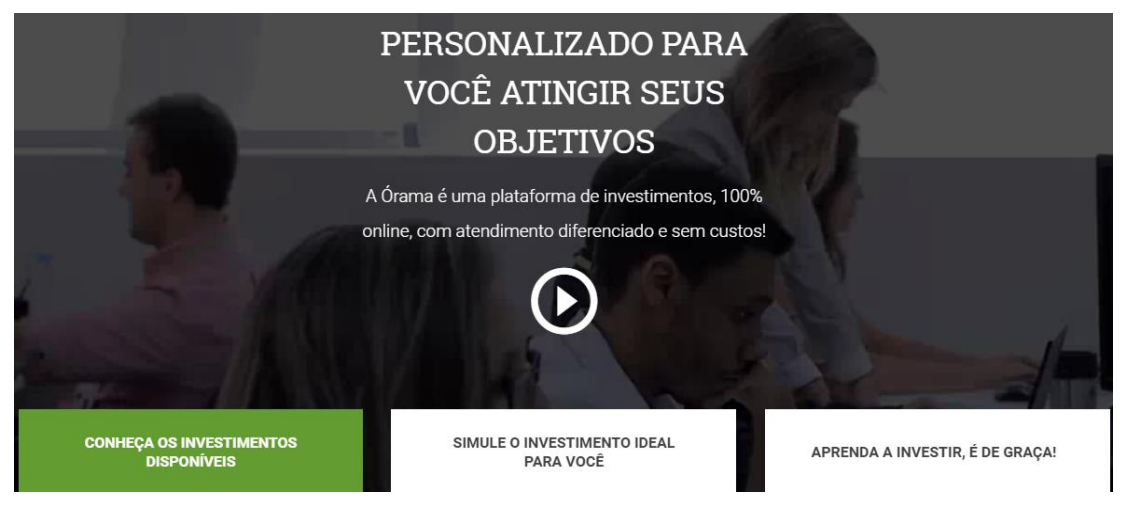

Figura 9: Banner Home - Órama Investimentos

Já a figura 10, demonstra o banner da Rico.com.vc, que já trata mais diretamente de um tipo de produto que a empresa oferece: os Títulos de Renda Fixa. A linguagem é bastante direta, reduzida e simples, falando dos principais argumentos de venda do produto em questão.

\footnotetext{
${ }^{3}$ Banner de entrada é a imagem inicial que aparece no momento de acesso à página principal do site.
} 


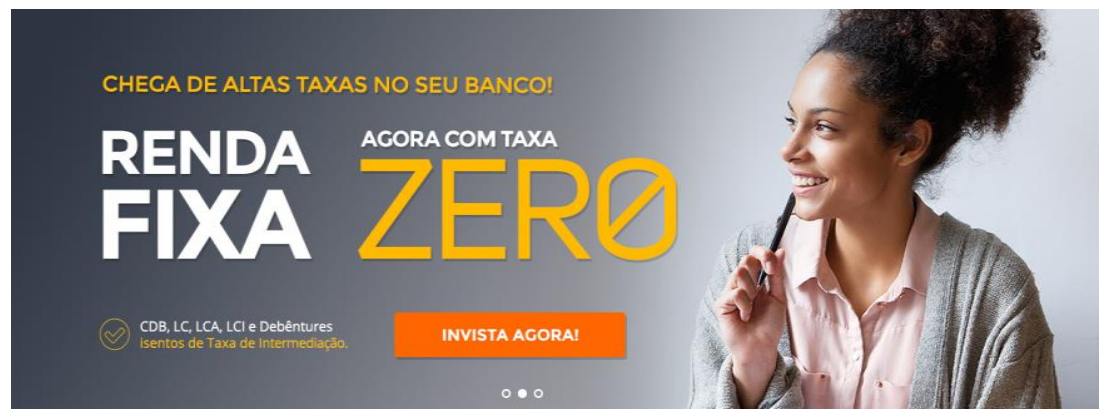

Figura 10: Banner Home - Rico.com.vc

$\mathrm{Na}$ figura 11, a XP investimentos, faz uma campanha institucional. Vendendo seus serviços puramente, sem tratar de produto. Mais uma vez, são alocados no banner os principais argumentos de venda, mas dessa vez tratando dos atributos da empresa como um todo.

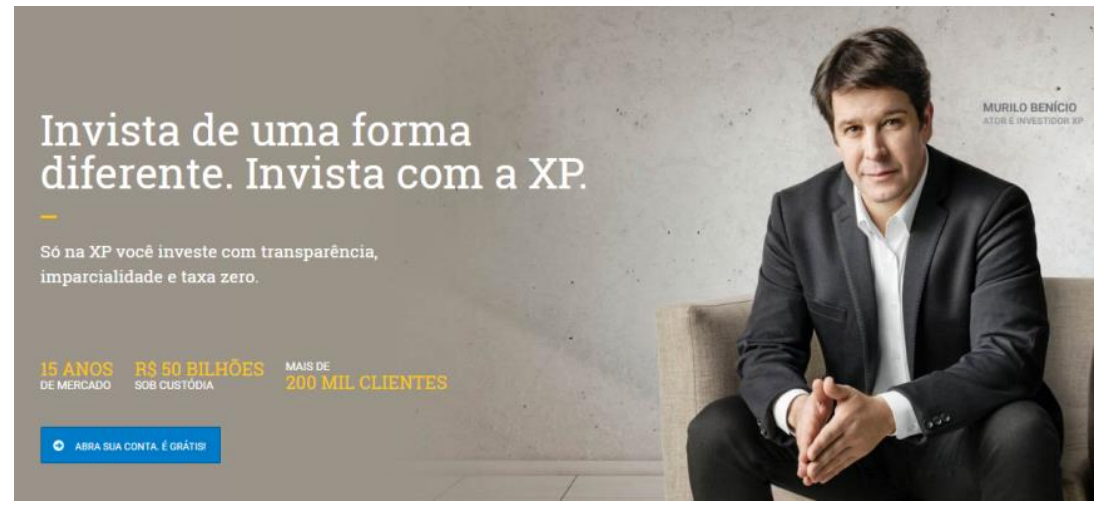

Figura 11: Banner Home - XP Investimentos

A última figura desta sessão - 12 - indica o banner utilizado na Home da Easynvest. Já este último, se distancia mais da ideia de banner. Mais curto e menos elaborado, ele usa um slogan se tratando sobre um produto em relação ao mercado, sem expor seus argumentos de venda.

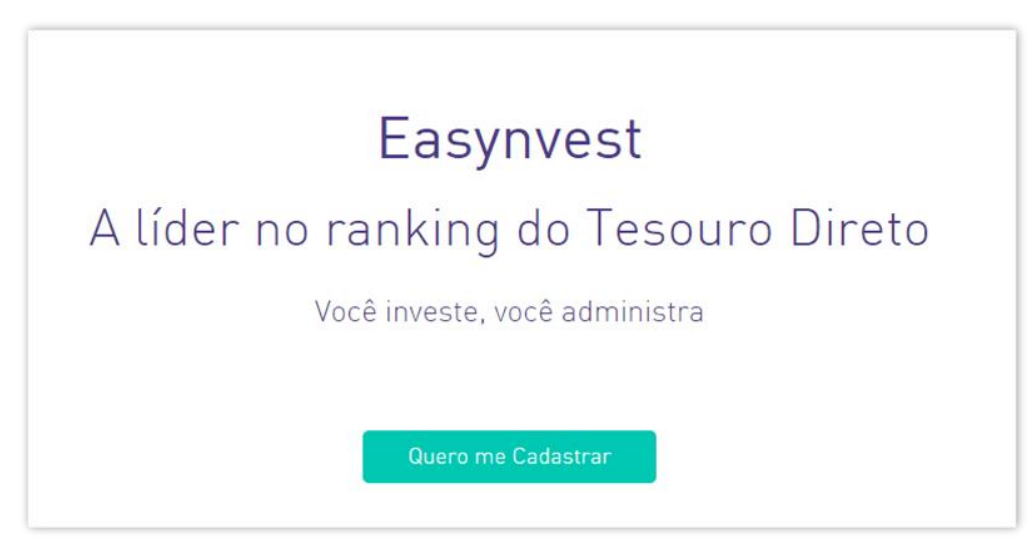

Figura 12: Banner Home - Easynvest

É essencial para a empresa em questão que ela entenda em qual estágio de compra o consumidor se encontra. De acordo com o modelo AIDA, divide-se os consumidores nos seguintes passos: atenção, interesse, desejo e ação (KOTLER, 2012). 


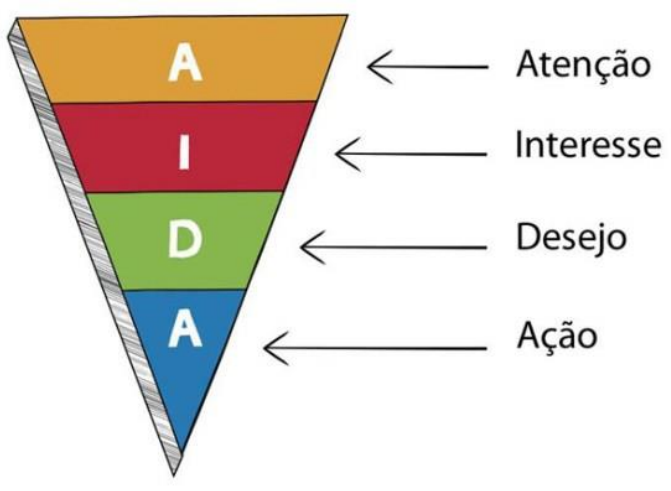

Figura 13: Modelo AIDA - Adaptado de Kotler

A comunicação deve chamar a atenção do mercado-alvo, gerar interesse ao informar o valor dos produtos, proporcionar um desejo de obter aquilo e oferecer incentivos para facilitar a ação de compra. Esse estudo da comunicação é essencial na hora de construir a página inicial do site, pois dependendo do passo de compra em que o usuário se encontra, deve ser tratado de maneiras diferentes, ou seja, a marca deve oferecer conteúdos diferentes de acordo com as necessidades de cada um.

Para elaborar melhor a estratégia de comunicação que as empresas devem efetuar é necessário identificar inicialmente o objetivo daquela comunicação. De acordo com (John R Rossiter e Larry Percy, 1885), existem 4 objetivos possíveis: necessidade da categoria, conscientização da marca, atitude em relação à marca e intenção de compra da marca. Como aprofundado neste trabalho, a empresa deve entender o seu público para elaborar suas peças de acordo com a comunicação mais adequada. $\mathrm{Na}$ home do site da Órama Investimentos, a divisão em três perfis diferentes ocorre justamente para tentar ser eficiente na comunicação com diferentes usuários, ou seja, ter maior nível de conversão.

"O processo de elaboração da comunicação para que se obtenha a resposta desejada requer a solução de três problemas: o que dizer, como dizer e quem deve dizer" (KOTLER, 2012). Ou seja, primeiro devemos definir a estratégia da mensagem de modo que ela esteja de acordo com o posicionamento da marca, seus apelos e temas. Em seguida surge a estratégia criativa, como a mensagem é expressa, se deveria ser utilizado um apelo informativo ou transformacional. Por último a fonte da mensagem, quem está passando o recado que você deseja entregar ao seu cliente. As figuras tratadas nesta seção passam as informações citadas acima. Por mais que sejam uma amostra pequena das comunicações da empresa, é possível obter pistas do seu posicionamento e quais os apelos e temas que estão dando maior relevância. 
Em estudo da Revista de Administração IMED, 2016, a comunicação e o marketing vêm passando por grandes transformações. Atualmente é necessário explorar a produção de conteúdos com formatos e linguagens bastante segmentadas ao público-alvo, para proporcionar maior interação, atratividade e identificação com os usuários. De acordo com Tur-Viñes e Monserrat-Gauchi (2015, p. 91), "agora o foco é o consumidor e a capacidade das marcas de dialogar e estabelecer relações emocionais com os consumidores". Nas páginas das concorrentes, podemos ver que as comunicações, apesar de diferentes entre si e focadas em assuntos mais complexos, tentam se aproximar de uma linguagem simples e atrativa, levando o consumidor a ter mais identificação para se aprofundar no tema.

Já em outro estudo feito pela revista Gestão e Tecnologia, 2015, (Comunicação nas Mídias Sociais sobre o Consumidor: Uma Replicação do Estudo de Schivinski e Dabrowski), foi indicado que as comunicações feitas pelas empresas no seu Facebook são mais influenciadoras da percepção geral do consumidor que as informações colocadas pelos próprios usuários. Ou seja, essa percepção afeta de maneira positiva a relação e o valor com a marca. De acordo com esse estudo, é de extrema importância que as empresas estejam atentas à sua estratégia de comunicação nas redes, não só com o que falam delas, mas sim com as suas postagens.

Na revista Brasileira de Marketing (Estudo exploratório sobre o uso das redes sociais na construção do relacionamento com clientes, ROCHA, T. V.; JANSEN, C. L. S.; LOFTI, E.; FRAGA, R. R., 2013), foi possível encontrar um artigo que diz bastante sobre os novos consumidores, que chamam de "geração internet". A expectativa do público atual é de serviços que contem com customização, diversão e inovação, e a grande dificuldade aparece nesse momento: "como atingir tais expectativas em ambientes intangíveis". Essa realidade se torna ainda mais difícil quando se trata de um serviço $100 \%$ online e um tema complexo. A Órama, ao dividir em 3 perfis diferentes, está justamente tentando falar com 3 públicos diferentes, oferecendo materiais distintos para cada um deles. A ideia é pensar sempre no cliente em primeiro lugar e entender ao máximo suas necessidades e preferenciais para obter o melhor resultado possível com o autoatendimento.

Holt, 2016, Em artigo do site Harvard Business Review - Branding in the Age of Social Media - é citado o conceito de "Crowdcultures".

"As tecnologias digitais não só criaram

novas redes sociais potentes, mas também 
alteraram dramaticamente a forma como a cultura funciona. As multidões digitais servem agora como inovadores muito eficazes e proliferadores da cultura - um fenômeno que chamo de multidão cultural. " (P.1)

O autor recomenda que as empresas devem procurar atingir multidões de culturas parecidas, de maneira bastante segmentada, para que através delas as informações e conteúdos sejam viralizadas e atinjam um maior número de consumidores interessados no assunto.

Outro fator bastante relevante é que, apesar da entrada do mercado financeiro nas redes sociais ser bastante recente, elas já são muito exploradas pelas empresas mais "informais" do ramo. Além disso, ainda não existem estudos ou casos que comprovam a efetividade dessas novas formas de se comunicar com o público alvo, mas é possível analisar as melhores respostas na própria internet.

A easynvest pode ser vista como um bom exemplo. Bastante ousada em suas comunicações e com uma linguagem mais simples, ela tem bom índice de resposta, altos números de likes e de engajamento no geral com as suas peças. Temos exemplo, na figura 14, de uma peça que colocaram no Facebook com o seguinte texto: "Chega de trabalhar a semana toda para os outros e só poder mostrar o seu talento na cozinha no almoço de domingo. Hora de colocar a sua grana para investir, levar os seus dotes culinários para as ruas e finalmente ser 0 seu próprio patrão. \#InvestirPodeSerAtéDivertido\#EspíritoEmpreendedor". A imagem é bem simples e sem muita informação e o texto faz uma brincadeira tentando incentivar as pessoas a começar a investir. Apesar dos comentários (14), em sua maioria, serem negativos, ela tem um grande número de curtidas (3 mil).

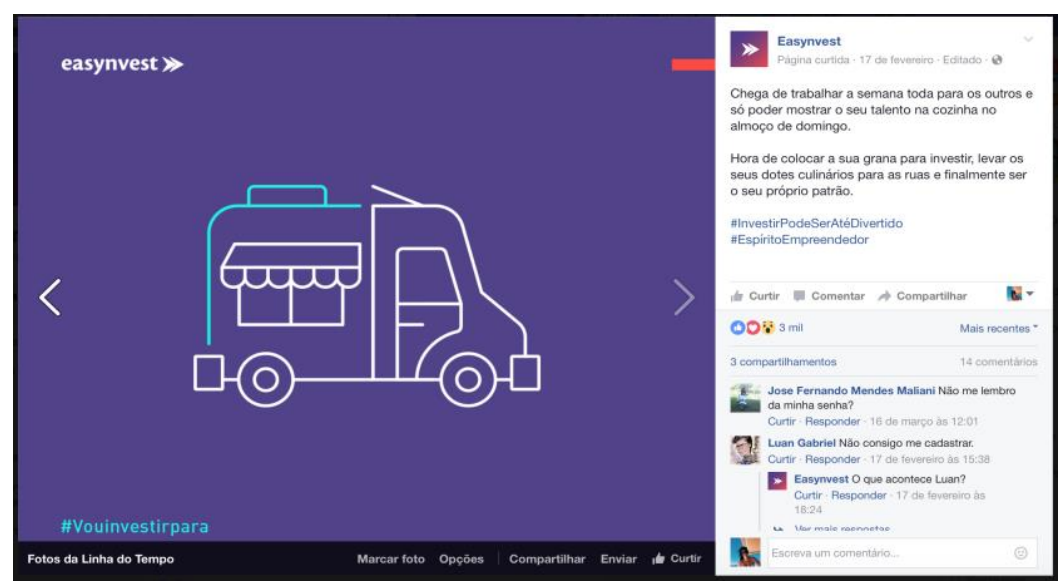

Figura 14: Post - Facebook Easynvest

Ao analisar as páginas nas redes sociais de outras concorrentes, 
podemos notar que ainda são bastante incipientes e é comum ter comentários muito negativos nas postagens, o que no geral não acontece com a Órama. 
Este capítulo pretende informar sobre as diversas decisões acerca da forma como este estudo foi realizado.

A empresa anuncia seus produtos a partir de banners nas redes sociais, sendo a principal rede, o Facebook. A pesquisa foi realizada com o objetivo de avaliar as comunicações da empresa e focou em duas peças.

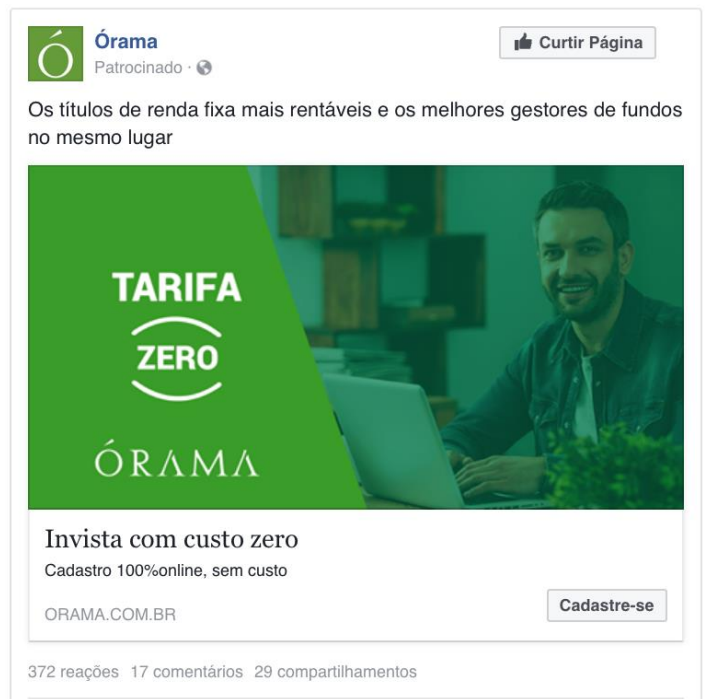

Figura 15: Anúncio Institucional - Facebook Órama

O anúncio representado na figura 14 teve seus resultados do dia 13 de abril até o dia 20 de abril analisados. $O$ anúncio, onde foram investidos $R \$$ $1.497,59$ no período em questão, resultou na finalização de 29 logins (primeiro passo do cadastro do cliente, onde informa somente seu nome e e-mail e cria uma senha de acesso) criados, ou seja, tendo um custo por login de $R \$ 51,68$. Além disso, houveram 46.135 pessoas alcançadas, ou seja, 46.135 pessoas foram atingidas - viram - pelo anúncio, 372 reações à postagem, 17 comentários e 29 compartilhamentos. 


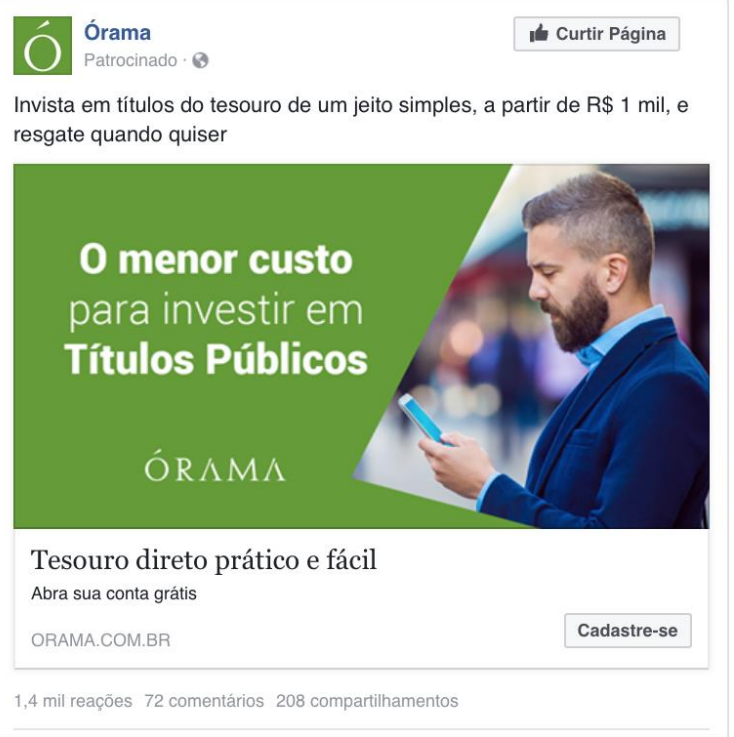

Figura 16: Anúncio Tesouro - Facebook Órama

O segundo anúncio em questão - figura 15 - trata da divulgação de um produto da empresa, o fundo Órama DI Tesouro. Nesse caso os resultados - de 17 à 20 de abril - foram bem mais elevados e o investimento extremamente inferior, de $R \$ 53,80$ reais. O anúncio obteve 72 comentários, 208 compartilhamentos e um total de 1,4 mil reações. O alcance (número de usuários que viram a peça) total do anúncio foi de 3.24 e converteu em 12 logins criados. Apesar dos números de cadastros e alcance ser menor, o custo por resultado ficou em $R \$ 4,48$.

Outro ponto importante para esta análise é o resultado encontrado no Google Analytics. Na figura 15 podemos temos destacado o resultado do facebook do dia 17 à 20 de abril. A partir do anúncio, sabemos que foram feitas 11 aplicações na plataforma da Órama, totalizando $R$ \$ 64.601,05 investidos, 32 logins criados e um cadastro completo. Esse resultado é relacionado aos anúncios pagos do facebook, que nesse período de tempo, teve um total de $R \$ 4.002,24$ investidos, ou seja, um custo aproximado de $\mathrm{R} \$ 125,07$ por login criado.

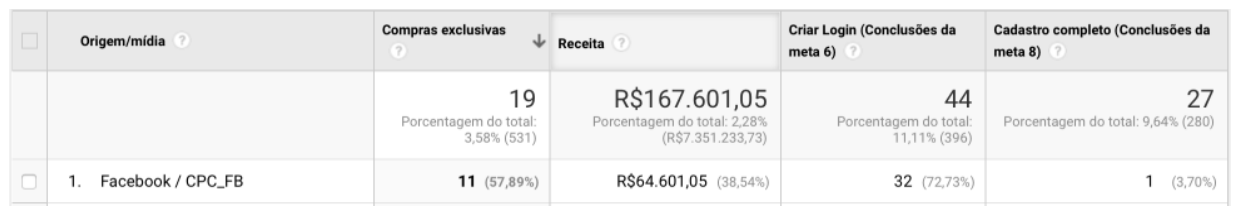

Figura 17: Tabela Google Analytics - Facebook Órama

\subsection{Análise das entrevistas}

Após a análise dos anúncios, a fim de complementar o estudo e obter mais insights, foram realizadas entrevistas com 4 profissionais de 
marketing digital.

De acordo com os depoimentos recolhidos, algo que se repetiu com bastante frequência, foi o desafio de estarem sempre se atualizando com as novidades das ferramentas de mídia digital. Por ser uma mídia extremamente nova, dizer estar em constante aprimoramento, e por isso, sempre fazendo alterações na forma em que o profissional deve utilizá-la.

Em entrevista com ED, a profissional ressaltou a importância de entender grandes diferenças entre o marketing offline e o digital. De acordo com ela, as empresas devem conseguir traduzir os seus objetivos em KPIs (Key Performance Indicator) ${ }^{4}$ do marketing digital para conseguir fazer as métricas e acompanhamentos adequados a eles. Nesse caso, talvez não haja uma venda direta, mas sim um auxílio na jornada de compra do consumidor, criando uma experiência diferente para o usuário. Ou seja, o profissional deve entender profundamente quais os objetivos daquela campanha e a melhor forma de acompanhar de modo a obter o melhor resultado possível.

Ao questionar sobre os canais mais efetivos do marketing digital, entrevistados deram respostas parecidas, com grande foco em Google Adwords. No caso de ED, ela acredita que não é possível citar um canal específico de maior eficiência, mas que cada um tem um objetivo diferente e a campanha deve estar inserida no canal mais adequado.

$\mathrm{Na}$ terceira pergunta da entrevista, os entrevistados concordaram que para encontrar o melhor público, é necessário "olhar para dentro", interpretar os clientes atuais, entendê-lo profundamente para elaborar as campanhas já focadas no usuário alvo. Além disso, foi ressaltado a importância de observar os resultados de campanhas anteriores para aplicar as melhorias e alterações na seleção do público-alvo das seguintes.

Na última pergunta da entrevista, era questionada a melhor forma de atingir diferentes públicos, em momentos diferentes de compra. Nesse caso, as respostas reforçam o fato de que as empresas devem tratar esses diferentes alvos com campanhas distintas, formatos distintos e canais distintos. ED citou o conceito de micro momentos, reforçando a importância de entender o usuário para saber exatamente as necessidades e comportamento dele para entregar o conteúdo que deseja da maneira mais

\footnotetext{
4 “É um Indicador-chave de Performance. É uma forma de medir se uma ação ou um conjunto de iniciativas estão efetivamente atendendo aos objetivos propostos pela organização". Website Marketing de Conteúdo.
} 
efetiva e eficiente possível.

Em entrevista com a gerente de marketing da Órama - CB, foram ressaltados dois principais pontos: Atualização constante e Segmentação. Para ela, o profissional de marketing deve estar 100\% mergulhado no mundo digital, se atualizando com muita frequência para que não perca a oportunidade de atingir novos usuários e de maneiras mais eficazes e efetivas. Já no caso da segmentação, devemos focar na extrema necessidade de entender o público e atingir as "pessoas certas" para obter uma melhor conversão. Para ela, quanto mais segmentada for a campanha, ou seja, quanto mais focadas forem as comunicações, melhor vai ser o seu resultado. 
Esse capítulo apresenta e analisa os resultados mais relevantes da pesquisa de campo, confronta

Após o fim das pesquisas, a autora pôde fazer algumas conclusões com relação ao objetivo do trabalho. Para desenvolver a estratégia de comunicação online de maneira mais adequada para conseguir atrair e converter o público alvo da Órama DTVM a empresa deve canalizar seus esforços para fazer a segmentação mais profunda e adequada possível. É indicado que construam as personas ideais da marca e em cada elaboração de campanha, sejam feitas diferentes versões. Desta forma, a marca consegue atingir leads mais qualificados e com maiores chances de conversão.

Além disso, os funcionários de marketing da empresa devem estar constantemente atualizados e para isso é interessante que participarem de eventos de atualização no marketing digital. A empresa deve procurar estar sempre à frente das tecnologias e dos lançamentos da internet, a fim de não perder nenhum tipo de melhoria em suas atuações e conversões. 


\section{Referências Bibliográficas}

ALBUQUERQUE, E. A importância do atendimento personalizado e qualificado no marketing de serviços. O case da XP Investimentos. Rio de Janeiro, 2011. TCC (Graduação em Administração) - Departamento de Administração: Pontifícia Universidade Católica do Rio de Janeiro.Organização para a Cooperação de Desenvolvimento Econômico. How's life in Brazil?. New York, 2016.

ANBIMA. Consolidado Histórico de Fundos de Investimento, fev. 2017. Disponível na Internet: http://www.anbima.com.br/pt_br/informar/estatisticas/fundos-deinvestimento/fi-consolidado-historico.htm. Acesso em: 21 de abril de 2017.

ARTHMAR, R. Os Estados Unidos e a economia mundial no Pós-primeira guerra. FGV, Rio de Janeiro, 2002. Disponível em: <http://bibliotecadigital.fgv.br/ojs/index.php/reh/article/viewFile/2156/1295>. Acesso em: 02 de dezembro de 2016.

Associação Brasileira das Entidades dos Mercados Financeiros e de Capitais. Balanço de Iniciativas. Educação 2016. Rio de Janeiro, 2016 Disponível em: <http://portal.anbima.com.br/a-anbima/educacao-doinvestidor/Documents/Balanco_Iniciativas_2016.pdf>. Acesso em: 02 de dezembro. 2016.ALVARENGA, D. Concentração aumenta e 5 bancos já detêm mais de $80 \%$ dos ativos do país. Globo, São Paulo, 03 ago. 2015. Disponível em: <http://g1.globo.com/economia/noticia/2015/08/concentracao-aumenta-e-5-bancosja-detem-mais-de-80-dos-ativos-no-pais.html>. Acesso em: 27 de junho de 2005.

Banco Central do Brasil. O que são a corretora e a distribuidora de títulos e de valores mobiliários?. Disponível em: <http://www.bcb.gov.br/pre/composicao/corretoras_distribuidoras.asp>. Acesso em: 02 de dezembro de 2016.

BORTOLOZI, T. Setor de telecomunicações lidera reclamações do Procon; veja ranking. Folha de S. Paulo, São Paulo, 22 jun. 2005. Disponível em: 
<http://www1.folha.uol.com.br/fsp/dinheiro/fi2206200522.htm>. Acesso em: 02 de dezembro de 2016.

Bremenkamp Consultoria Financeira. Desbancarização: o que é e com funciona. Disponível em: < http://bremenkampcf.com/desbancarizacao-o-que-e-e-comofunciona/>.

Comissão de Valores Mobiliários. Decisão-Conjunta №17. Rio de Janeiro, 2009. Disponível em: $<$ http://www.cvm.gov.br/export/sites/cvm/legislacao/conj/anexos/dcbccvm17.pdf>. Acesso em: 02 de dezembro de 2016.

DAMACENA, C.; PETROLL, M. M.; VONTOBEL, J. K. Os Efeitos da Comunicação nas Mídias Sociais sobre o Consumidor:Uma Replicação do Estudo de Schivinski e Dabrowski(2014) . Revista Gestão \& Tecnologia, v. 15, n. 2, p. 135-160, 2015.

FRIEDRICH, M. P. A.; BASSO, K.; FROEMMING, L. M. S.; BASEGGIO, H. W. O Treinamento de Clientes e sua Relação com a Intenção de Uso do Internet Banking. Revista Brasileira de Marketing, v. 15, n. 5, p. 655-668, 2016.

Globo. Veja perguntas e respostas sobre as mudanças na poupança. São Paulo, 10 mai. 2012. Disponível em: <http://g1.globo.com/economia/seudinheiro/noticia/2012/05/veja-perguntas-e-respostas-sobre-mudancas-napoupanca.html>. Acesso em: 02 de dezembro de 2016.

GOLDNER, F. Estratégia de Fusão e Aquisição Bancária no Brasil: Evidências Empíricas sobre Retornos. Fucape, Espírito Santo, 2003. Disponível em: $<$ http://www.fucape.br/_public/producao_cientifica/2/goldner\%20\%20estrategia\%20de\%20fusao\%20e\%20aquisicao.pdf $>$. Acesso em: 2 de dezembro de 2016.

HAHN, I. S.; SCHERER, F. L.; BASSO, K.; SANTOS, M. B. D. Consumer Trust in and Emotional Response to Advertisements on Social Media and their Influence on Brand Evaluation. Brazilian Business Review, v. 13, n. 4, p. 49-71, 2016.

HOLT, D. Branding in the Age of Social Media. Harvard Business Review, mar. 2016. Disponível em: <https://hbr.org/2016/03/branding-in-the-age-of-social-media>. Acesso em: 24 abr. 2017. 
Instituto Brasileiro de Geografia e Estatística. Projeção da População do Brasil e das Unidades da Federação. Rio de Janeiro, 2016 Disponível em: <http://www.ibge.gov.br/apps/populacao/projecao/>. Acesso em: 02 de dezembro. 2016.

Investment Company Institute. 2016 Investment Company Fact Book. Rio de Janeiro, 2016 Disponível em: <https://www.ici.org/pdf/2016_factbook.pdf>. Acesso em: 02 de dezembro. 2016.

JUNIOR, J. PAULA, L. Fusões e aquisições bancárias e a evolução da eficiência técnica dos maiores bancos privados no Brasil. Anpec, Rio de Janeiro, 2016 Disponível em: <http://www.oecdbetterlifeindex.org/topics/income/>. Acesso em: 02 de dezembro. 2016.

KOTLER, P. KELLER, K. Administração de Marketing. São Paulo: Pearson, 2012.

LAURENSON, L. Social Media Platforms Can Be Built Around Quality, Not Scale. Harvard Business Review, 06 abr. 2017. Disponível em: $<$ https://hbr.org/2017/04/imagining-a-social-media-platform-built-around-quality-notscale>. Acesso em: 24 abr. 2017.

Marketing de Conteúdo. KPI: Descubra o que é e como ele ajuda a medir seus resultados! Disponível em: <http://marketingdeconteudo.com/kpi/>

Marketing de Conteúdo. O que é mesmo engajamento? Disponível em: $<\mathrm{http}: / /$ marketingdeconteudo.com/kpi/>

OECD. Education at a Glance interim report: update of employment and educational attainment indicators. New York, 2016.

Organização para a Cooperação de Desenvolvimento Econômico. Consumer Confidence Index. Rio de Janeiro, 2016 Disponível em: $<$ https://data.oecd.org/leadind/consumer-confidence-index-cci.htm>. Acesso em: 02 de dezembro. 2016.

Organização para a Cooperação de Desenvolvimento Econômico. Education Brazil. Rio de Janeiro, 2016 Disponível em: $<$ http://www.oecdbetterlifeindex.org/topics/education/>. Acesso em: 02 de dezembro. 
2016.

Organização para a Cooperação de Desenvolvimento Econômico. Income - Brazil. Rio de Janeiro, 2016 Disponível em: <http://www.oecdbetterlifeindex.org/topics/income/>. Acesso em: 02 de dezembro. 2016.

Organização para a Cooperação de Desenvolvimento Econômico. Jobs - Brazil. Rio de Janeiro, 2016 Disponível em: <http://www.oecdbetterlifeindex.org/topics/jobs/>. Acesso em: 02 de dezembro. 2016.

Organização para a Cooperação de Desenvolvimento Econômico. Trabalhando com 0 Brasil. Paris, 2015.2 Disponível em: <http://www.oecd.org/brazil/Brazil\%20brochure\%20final\%20[Port]\%201\%20[WEB].pd f>. Acesso em: 02 de dezembro. 2016.

PEREIRA, P. A. A satisfação e confiança do consumidor nos ambientes virtuais de corretoras de valores. Rio de Janeiro, 2009. TCC (Graduação em Administração) - Departamento de Administração: Pontifícia Universidade Católica do Rio de Janeiro.

Portal Brasil. Entenda a mudança nas poupanças. Rio de Janeiro, 2012 Disponível

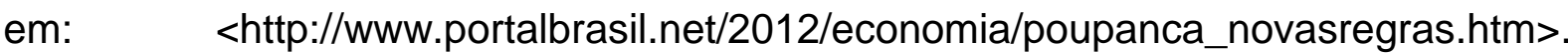
Acesso em: 02 de dezembro. 2016.

Programa de proteção e defesa do consumidor. Cadastro de Reclamação Fundamentada. Rio de Janeiro, 2016. Disponível em: <http://www.procon.rj.gov.br/procon/assets/arquivos/arquivos/rel_reclamacao_funda mentada_jan2015_-_dez2015_1458046042.1.pdf>. Acesso em: 02 de dezembro. 2016.

QUEIROZ, L. S.; BERGAMO, F. V. M.; MELO, J. S. Validação de um Modelo Conceitual de Experiência de Compra Online para Consumidores Brasileiros. Revista Brasileira de Marketing, v. 15, n. 4, p. 524-539, 2016.

ROCHA, T. V.; JANSEN, C. L. S.; LOFTI, E.; FRAGA, R. R. Estudo exploratório sobre o uso das redes sociais na construção do relacionamento com clientes. Revista Brasileira de Gestão de Negócios, v. 15, n. 47, p. 262-282, 2013. 
ROHDEN, S. F.; MATOS, C. A.; CURTH, M. Intenções de Recompra e Confiança do Consumidor On-Line. Revista de Ciências da Administração, v. 18, n. 45, p. 9-24, 2016.

SCHWARTZ, J. EMRICH, O. MOCHON, D. JOHN, L. What's the Value of a Like? Harvard Business Review, mar. 2017. Disponível em: <https://hbr.org/2017/03/whatsthe-value-of-a-like>. Acesso em: 24 abr. 2017.

SILVA, G. E.; ZACCARIA, R. B.; PITOMBO, T. D. T.; MONTEIRO, T. A. Eye Tracking e Métricas na Web como Ferramentas para Estratégias Inovadoras de Comunicação. Revista de Administração IMED, v. 6, n. 1, p. 91-104, 2016.

SOLOMON, M. O comportamento do consumidor. Porto Alegre: Bookman, 2011.TEIXEIRA, C. DANTAS, G. Fusão e aquisição na indústria bancária brasileira - estudo de caso Itaú-Unibanco. Aedb, Rio de Janeiro, 2015.

TARABORELLI, A. Investidor busca aplicações mais rentáveis fora dos bancos. Brasil Econômico, 04 mai. 2015. Disponível em: $<$ http://brasileconomico.ig.com.br/financas/2015-05-04/investidor-busca-aplicacoesmais-rentaveis-fora-dos-bancos.html>. Acesso em: 24 abr. 2017.

WENNA, Y. M. Perspectivas das corretoras brasileiras no atendimento às pessoas físicas. Rio de Janeiro, 2005. TCC (Graduação em Economia) Departamento de Economia: Pontifícia Universidade Católica do Rio de Janeiro. 


\section{Anexo 1: Roteiro das entrevistas}

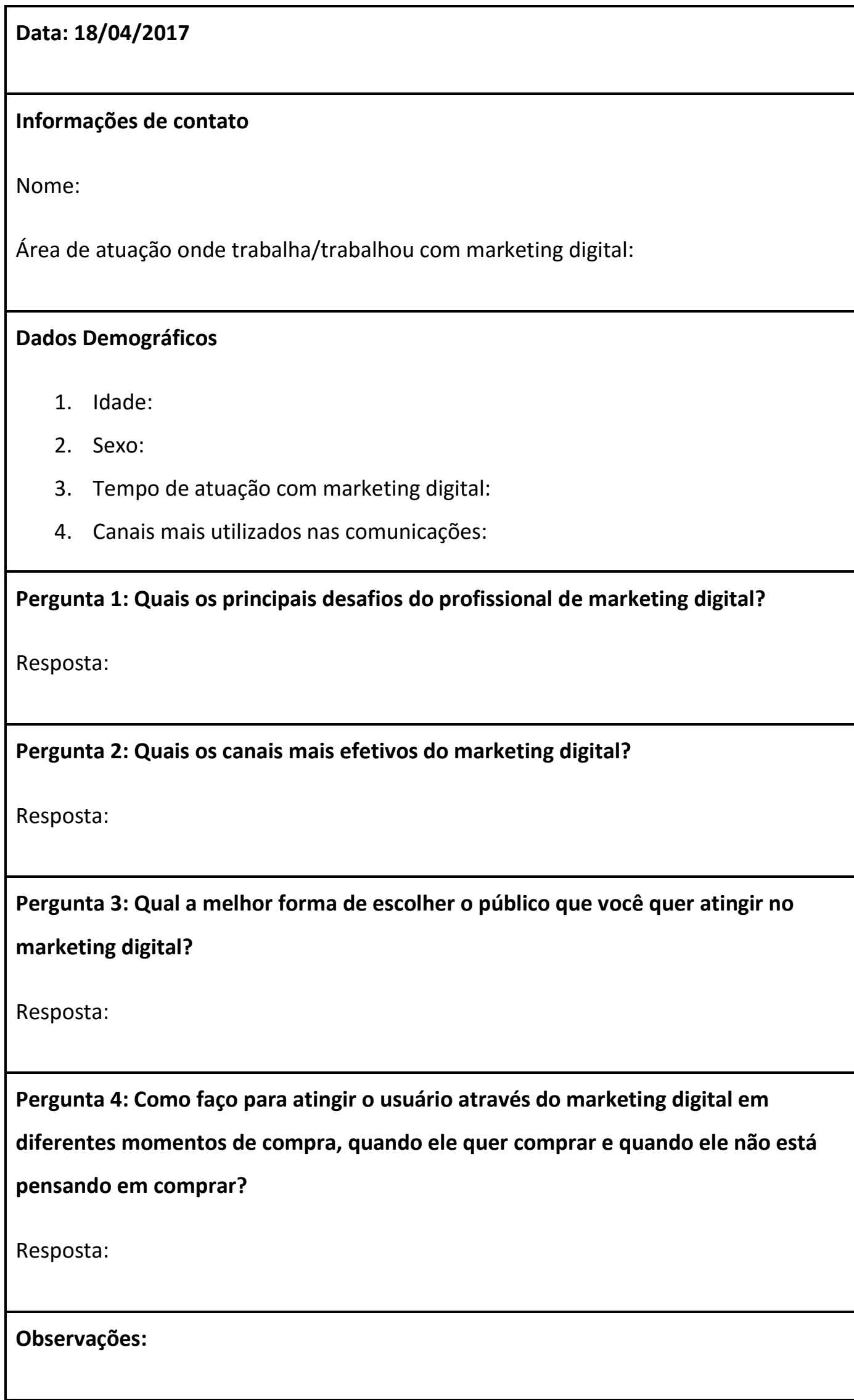




\section{Anexo 2: Convite Entrevistas}

Alessandra Baiocchi

7 de abril

Queridos! Preciso de ajuda... Tenho uma aluna, a Rafaela Nissenbaum, que está fazendo seu TCC sobre Marketing Digital. Precisa entrevistar profissionais da área. Algum de vocês trabalha com Digital? Poderia conceder uma breve entrevista? Obrigada!

Curtir Comentar 